\title{
Lipids in hairy roots and non-Agrobacterium induced roots of Crambe abyssinica
}

\author{
Bartosz Głąb • Tomasz Furmanek • \\ Magdalena Miklaszewska • Antoni Banaś • \\ Aleksandra Królicka
}

Received: 19 September 2012/Revised: 19 February 2013/ Accepted: 25 February 2013/Published online: 6 March 2013

(C) The Author(s) 2013. This article is published with open access at Springerlink.com

\begin{abstract}
Hairy root cultures of Crambe abysinica were obtained through infection of leaves with two wild-type agropine strains of Agrobacterium rhizogenes. The efficiency of transformation was about $16 \%$. The presence of T-DNA from A. rhizogenes in the hairy roots genome was confirmed by PCR using specific primers for rolB and rolC genes. Selected clones of hairy roots and non-Agrobacterium induced roots from sterile cultures were used for analyses of acyl-lipids. The total amount of acyl-lipids per $\mathrm{mg}$ of dry weight was similar in both the non-Agrobacterium induced roots and the hairy roots in good physiological condition, and ranged from 38 to $53 \mathrm{nmol}$. However, in the clones which showed symptoms of ageing, the lipid content was severely reduced. Also the lipid composition of hairy roots appears to be similar to the composition of non-transformed roots. Polar lipids were the dominant class of lipids in both types of roots (about $75 \%$ ). Furthermore, we found diacylglycerols, free fatty acids (FFA), triacylglycerols, sterol esters, and an unidentified lipid class. The dominant fatty acids in the lipids of both types of roots were $\alpha$-linolenic acid, palmitic acid, and linoleic acid (over $12 \%$ of total FA). Among the lipids of both hairy roots and non-Agrobacterium induced roots of
\end{abstract}

Communicated by M. Capuana.

B. Głąb · M. Miklaszewska · A. Banaś · A. Królicka ( $\)$ Department of Biotechnology, Intercollegiate Faculty of Biotechnology, University of Gdańsk and Medical University of Gdańsk, Kładki 24, 80-822 Gdańsk, Poland

e-mail: krolicka@biotech.ug.edu.pl

T. Furmanek

Institute of Biology and Environmental Protection, Pomeranian University in Słupsk, Arciszewskiego 22b, 76-200 Słupsk, Poland
C. abyssinica, an unidentified FA was found (over $16 \%$ of total FAs). The present study is the first example of establishment of hairy roots cultures of $C$. abyssinica. It also includes the first analysis of the lipids in hairy roots and non-Agrobacterium induced roots of this species.

Keywords Agrobacterium rhizogenes . Crambe abyssinica $\cdot$ Lipid · Transformation
Abbreviations
AC Acetosyringone
DAG Diacylglycerols
DW Dry weight
FA Fatty acids
FFA Free fatty acids
FS Free sterols
GC Gas chromatography
HEAR High erucic acid rape
LEAR Low erucic acid rape
PVP Polyvinylpyrrolidone
PUFA Polyunsaturated fatty acid
SE Sterol esters
TLC Thin layer chromatography
TAG Triacylglycerols

\section{Introduction}

Crambe abyssinica (Abyssinian mustard) is a Mediterranean native oilseed crop belonging to the Brassicaceae family. Its oil contains a high amount of erucic acid (55-60\%) and is, therefore, used almost exclusively for industrial purposes. Present uses of crambe oil include lubricants, corrosion inhibitors, surfactants, coating agents, 
and anti-sticking agents. Its oil is more interesting to the chemical industry than high erucic acid rape (HEAR) oil, due to lower amounts of polyunsaturated fatty acids (PUFAs) (Nath et al. 2007). C. abyssinica is also an ideal species for genetic manipulations aimed at improving its industrial suitability. It does not cross-breed with other cultivated plants, or with the majority of related wild species (Wang and Peng 1998). Currently, C. abyssinica is cultivated only in a few countries, on very limited areas. Therefore, a potential new, transgenic variety of $C$. abyssinica would probably be spatially separated from classic varieties. However, even if mixing occurred by chance, it would not have any effect on the consumers, as crambe's oil is not edible.

All the above-mentioned unique characteristics of C. abyssinica contribute to its growing popularity among plant biotechnologists. $C$. abyssinica transformation methods developed so far use Agrobacterium tumefaciens as the vector ( $\mathrm{Li}$ et al. 2010; Engler and Montanez 2010). Still, these methods were shown not to be very efficient. The aim of this study was to develop an alternative transformation method using Agrobacterium rhizogenes. This bacterium is an etiological agent of the hairy root disease, which is caused by incorporation of a bacterial-derived segment of transferred-DNA (T-DNA), containing root loci (rol) genes, into the chromosomes of plant cells (Hunter and Neill 1990). However, laboratory strains without these genes are available that can be used to introduce other genes into C. abyssinica genome (Mankin et al. 2007). Hairy root cultures can produce a spectrum of secondary metabolites that are not present in the parent plant (Tepfer 1984; Tiwari et al. 2008). This technique has become a useful tool for studying biochemical properties of plants (Cai et al. 2012). Laboratory protocols for hairy root induction involve cultivation of a wounded, sterile explant that has been either directly inoculated, or co-cultivated with an A. rhizogenes suspension, and then treated with antibiotics to eliminate the bacteria. Recent advances in hairy roots induction include introduction of a new technique-sonication-assisted A. rhizogenes-mediated transformation (SAArT) - which is particularly suitable for inducing hairy roots in recalcitrant plant species (Georgiev et al. 2012). Due to their fast growth rates and biochemical stability, hairy root cultures remain unsurpassed as a model root system and seem to be a promising bioprocess system (Cai et al. 2012).

In addition to the development of a new protocol of crambe transformation, another goal of this research was cultivation of stable hairy roots cultures of $C$. abyssinica. Hairy roots cultures offer genetic stability and dynamic growth without growth hormones (Hamill et al. 1987).
They can be used to produce different kinds of chemicals for industrial and pharmaceutical applications. Moreover, the potential of hairy roots of Echium acanthocarpum for production of polyunsaturated fatty acids (PUFAs) was investigated. Total amount of lipids obtained in different hairy root lines ranged from 29.75 to $60.95 \mathrm{mg} / \mathrm{g}$ dry weight (DW) and PUFAs accounted for approximately $55 \%$ of total FAs (Cequier-Sánchez et al. 2011). It may be possible to use hairy roots cultures in bioreactors for oil production, which would make them a viable alternative to oil seed crops. Nevertheless, the knowledge about lipids in hairy roots remains limited (Cequier-Sánchez et al. 2008, 2011; Toivonen et al. 1992). The results we present may be considered a first step in revealing the lipid metabolism of hairy roots and non-transformed roots of $C$. abyssinica.

\section{Materials and methods}

\section{Plant material}

Seeds of $C$. abyssinica cv. Mayer were surface-sterilised for 15 min in a $5 \%$ solution of $\mathrm{CaCl}_{2} \mathrm{O}_{2}$, mixed ( $1 \mathrm{drop} /$ $100 \mathrm{ml}$ ) with Tween 80 (POCh, Poland), rinsed four times with sterile, distilled water and placed in glass jars (capped with polypropylene lids) with agar-solidified medium ( $7.5 \mathrm{~g}$ agar $1^{-1}$; Sigma) containing $2 \%(\mathrm{w} / \mathrm{v})$ of sucrose (SigmaAldrich, Germany). The $\mathrm{pH}$ of the media was adjusted to 5.8 prior to autoclaving $\left(114^{\circ} \mathrm{C} ; 105 \mathrm{kPa}\right)$. The cultures were incubated at $20-22{ }^{\circ} \mathrm{C}$ under a 16 -h photoperiod (white cool fluorescent light, Philips, TLD $58 \mathrm{~W} / 84 \mathrm{o}$, 30-35 $\mu \mathrm{mol} \mathrm{m} \mathrm{m}^{-2} \mathrm{~s}^{-1}$ ), in a growth chamber, for 4 weeks. During this time, the seeds germinated and the seedlings reached several centimetres in length.

A. rhizogenes agropine strains: A4 (ATCC 31798)obtained from the Botanical Garden of Wroclaw, Poland), and ATCC 15834 (obtained from the Laboratoire Agronomie et Environnement, Ecole Nationale Superieure d'Agronomie et des Industries Alimentaires, Nancy, France) - were grown on a YEB agar-solidified medium at $26{ }^{\circ} \mathrm{C}$, in the dark. Before transformation, the bacteria were inoculated to liquid YEB medium (Miller 1972) or agarsolidified YEB medium supplemented with $200 \mu \mathrm{M}$ acetosyringone (AC), and cultured at $26{ }^{\circ} \mathrm{C}$ in the dark, for $24 \mathrm{~h}$. Liquid cultures were grown on a gyratory shaker at $260 \mathrm{rpm}$ to a final $\mathrm{OD}_{600}=0.6$.

Establishment of hairy root cultures

Transformation of $C$. abyssinica was obtained using two different protocols. In both of them, two wild-type 
agropine strains: A4 and 15834, were used with explants of leaves and cotyledons (100 pieces of each).

1. C. abyssinica explants (cotyledons and leaves) were inoculated using inoculating needles containing A. rhizogenes. After inoculation, the tissues were put on MS medium containing $200 \mu \mathrm{M} \mathrm{AC}$ and incubated in the dark, at $20-22{ }^{\circ} \mathrm{C}$. After 3 days of co-culture, they were transferred to fresh MS medium containing $500 \mathrm{mg}^{-1}$ carbenicillin (Polfa, Tarchomin, Poland) and $500 \mathrm{mg} \mathrm{l}^{-1}$ claforan (Hoechst, M. Roussel, Germany).

2. Overnight $A$ rhizogenes culture which grew in the presence of $200 \mathrm{mM}$ acetosyringone was diluted to $\mathrm{OD}_{600}=0.6$. Into the resulting suspension, we put explants of $C$. abyssinica (cotyledons, leaves) which were previously wounded with a needle. They were then sonicated (frequency $40 \mathrm{kHz}$, Polsonic, Poland) for $3 \mathrm{~s}$ at $20^{\circ} \mathrm{C}$. Next, the co-cultures were rinsed with sterile, distilled water and put on a solid MS medium. After 3 days, they were transferred to a solid MS medium containing carbenicillin and claforan (500 $\mathrm{mg} \mathrm{l}^{-1}$ each).

After 1 month, numerous, fine roots appeared on the leaves. After cutting off, they were put into liquid MS medium containing $0.1 \mathrm{mg} \mathrm{l}^{-1} \alpha$-naphthaleneacetic acid (NAA), carbenicillin and claforan (500 $\mathrm{mg} \mathrm{l}^{-1}$ each). Individual clones were cultured in the dark, at $22{ }^{\circ} \mathrm{C}$, with shaking $(110 \mathrm{rpm})$. The hairy root cultures were passaged on a new MS medium every 2-3 weeks. Antibiotics were added during the first 5-6 passages, until A. rhizogenes was eliminated from the cultures.

Hairy root cultures, free from bacteria, were maintained in the dark at $20 \pm 2{ }^{\circ} \mathrm{C}$, on a rotary shaker $(110 \mathrm{rpm}$, amplitude 9) in 250-ml flasks containing $35 \mathrm{ml}$ of liquid MS medium (without antibiotics) supplemented with $0.1 \mathrm{mg}^{-1}$ NAA and $0.1 \%$ polyvinylpyrrolidone (PVP, Sigma-Aldrich, Germany). Subcultures were made every 3 weeks. The results were expressed as percentage transformation frequency $(\%$ transformation frequency $=$ [number of explants producing hairy roots/total number of explants infected with $A$. rhizogenes] $\times 100)$. All the experiments were carried out in triplicate and the results were expressed as mean $\pm \mathrm{SD}$. Statistical analysis was performed according to Tukey (1953).

Transformation of $C$. abyssinica was confirmed, at the molecular level (presence of T-DNA fragment in the DNA of hairy roots), with PCR using primers shown in Table 1, according to the procedure described by Krolicka et al. (2010).

The non-Agrobacterium-induced roots of $C$. abyssinica used for the analysis came from a 1-month-old seedlings cultured in vitro on a MS medium solidified with agar.
Lipid analysis

In order to reduce the risk of oxidation, exposure of lipids to oxygen was minimised using nitrogen atmosphere whenever possible, in all operations. Extraction of lipids was done according to the modified method of Bligh and Dyer (1959). Apart from C. abyssinica hairy roots clones, non-transformed roots of $C$. abyssinica from in vitro cultures were analysed. Depending on the physiological condition of the analysed roots, different amounts of tissue were collected (from 300 to $800 \mathrm{mg}$ ). The tissues were homogenised in a glass homogenizer with the addition of $3.75 \mathrm{ml}$ of chloroform and fresh methanol mixture (ratio 1:2), and $1 \mathrm{ml}$ of $0.15 \mathrm{M}$ acetic acid. The homogenate was moved into a test tube and $1.25 \mathrm{ml}$ of chloroform and $1.25 \mathrm{ml}$ of water were added (in order to obtain phase separation). The mixture was shaken intensively and centrifuged at circa $1,000 \times g$ for $3 \mathrm{~min}$. The chloroform phase was transferred into a new tube and vaporised in a nitrogen atmosphere at $50{ }^{\circ} \mathrm{C}$. The resulting residue was dissolved in $2 \mathrm{ml}$ of chloroform and stored at $-20^{\circ} \mathrm{C}$, or used immediately for further analysis.

To determine the total content and composition of fatty acids in the acyl-lipids of the analysed roots, aliquots of the obtained chloroform fractions were vaporised under a nitrogen stream and the sediments were incubated at $90{ }^{\circ} \mathrm{C}$ for $40 \mathrm{~min}$ with $2 \mathrm{ml}$ of $2 \%$ sulphuric acid in dry methanol. Next, we added an internal standard (17:0-Memethyl ester of heptadecanoic acid; Sigma), $3 \mathrm{ml}$ of hexane (Merck, Germany), and $3 \mathrm{ml}$ of water. The mixtures were shaken intensively. After centrifugation (at $1,000 \times g$ for $3 \mathrm{~min}$ ), hexane fractions were retrieved, vaporised, and dissolved in a small amount of hexane. The analyses of methyl esters of fatty acids contained in the extracts were carried out on a Shimadzu gas chromatograph with a flame ionisation detector and a BPx70 SGE capillary column. Fatty acids were identified based on the retention times of standards (Larodan, Sweden). Determination of their content was carried out through comparison of their peak areas with the peak area of the internal standard (done automatically by a computer program).

Lipid composition of the analysed roots was determined through separation of chloroform extracts on TLC plates (silica gel 60; Merck) developed in hexane:diethyl ether:acetic acid (70:30:1, v/v/v—separation of neutral lipids). The lipids were localised through short exposure of the plates to iodine vapour and identified according to the standards co-chromatographed with the samples. The areas of silica gel containing the separated lipid classes were sprayed with distilled water and transferred into test tubes. Water was removed from the gel (small amounts of methanol were added and vaporised in a nitrogen atmosphere, at $50{ }^{\circ} \mathrm{C}$ ), and the lipids were methylated and analysed using GC as described above. 
Table 1 Primers used in the study

\begin{tabular}{lll}
\hline $\begin{array}{l}\text { Primer } \\
\text { name }\end{array}$ & Primer sequence $5^{\prime} \rightarrow 3^{\prime}$ & $\begin{array}{l}\text { Product length } \\
(\mathrm{bp})\end{array}$ \\
\hline rol B1 & GCT CTT GCA GTG CTA GAT TT & 423 \\
rol B2 & GAA GGT GCA AGC TAC CTC TC & \\
rol C1 & CTC CTG ACA TCA AAC TCG TC & 626 \\
rol C2 & TGC TTC GAG TTA TGG GTA CA & \\
vir G1 & ACT GAA TAT CAG GCA ACG CC & 273 \\
vir G2 & GCG TCA AAG AAA TAG CCA GC & \\
\hline
\end{tabular}

Double bonds of unidentified FAs were determined by silver ion thin layer chromatography. TLC plates were prepared by steady pouring of a silver ion solution ( $2.5 \mathrm{~g}$ of silver nitrate diluted in $2.5 \mathrm{ml}$ of water with addition of $11 \mathrm{ml}$ of acetone) on a silica gel 60 plate $(20 \times 20 \mathrm{~cm})$, evaporation of the solvents for $15 \mathrm{~min}$ at room temperature, and a 10-min activation at $100{ }^{\circ} \mathrm{C}$. The methylated lipid extract of the hairy roots clone which contained the highest amount of unidentified fatty acids was separated on such plate (development in hexane:diethyl ether:acetic acid-70:30:1, v/v/v). The six separated fractions of fatty acids methyl esters from the analysed sample (as well as the co-chromatographed standards-methyl esters of palmitic, stearic, oleic, linoleic, and $\alpha$-linolenic acid) were visualised by spraying with water and scraped from the plate into the test tubes. Lipids were then extracted from the scraped silica gel by a 15 -min sonication with addition of $3.75 \mathrm{ml}$ of chloroform:methanol (1:2) mixture. After centrifugation $(2,000 \times g$ for $5 \mathrm{~min})$, the extracts were moved to new test tubes, internal standard $(17: 0-\mathrm{Me})$ was added, and fatty acid methyl esters were extracted to the chloroform phase (addition of $1 \mathrm{ml}$ of $0.15 \mathrm{M}$ acetic acid, $1.25 \mathrm{ml}$ of water and $1.25 \mathrm{ml}$ of chloroform; vortexing, and centrifugation for $3 \mathrm{~min}$ at $1,000 \times \mathrm{g}$ ). After evaporation of the chloroform (nitrogen atmosphere, $50{ }^{\circ} \mathrm{C}$ ), residues were solubilised in a small amount of hexane and analysed by gas chromatography. All the results of the analyses of lipid composition and content are presented as arithmetic means $(n \geq 3)$ with standard deviation.

\section{Results and discussion}

Hairy roots

During 4 weeks of sterile culture, more than $90 \%$ of seeds of $C$. abyssinica germinated and produced few centimetre long seedlings. Leaves and cotyledons of 4-week-old plants were then inoculated with two agropine strains of A. rhizogenes: A4 and 15834, using two different methods. After 1 month, numerous frail hairy roots appeared at the points of injection on the leaf fragments (Fig. 1), but not on cotyledons. If the leaves were inoculated (using a needle) with A4 strain, the frequency of transformation was $16 \%$. Another A. rhizogenes strain, 15834, which was used in this method showed only $2 \%$ of effectiveness. In turn, the use of sonication for transformation provided $5 \%$ of effectiveness for 15834 strain and $1 \%$ for A4 strain. The choice of an appropriate A. rhizogenes strain had an important impact on the transformation efficiency. Agropine strains of $A$. rhizogenes (also used in this study) are regarded as the most virulent, due to the fact that their cells contain two T-DNA sequences on Ri plasmid, called the left (TL-DNA) and right (TR-DNA) region (David and Tempe 1988). According to Porter (1991), strain 15834 is more virulent than A4. However, in our experiments, application of A4 strain gave better results. Thus, it seems that the method of introduction of A. rhizogenes to the transformed plant tissues is as much important (or perhaps even more important) as the utilised bacterial strain.

The choice of plant material is crucial for successful transformation with A. rhizogenes. Usually, transformation of young tissues gives the best results (Bonhomme et al. 2000). Sometimes, only a defined part of the plant can be used. In the case of Ammi majus, for example, only the use of the first stem node allows to obtain hairy root cultures (Królicka et al. 2001). Tissue regeneration ability could be the key factor for a successful transformation process. For example, it was shown that all stem tissues of young Nicotiana tabacum plants were able to produce hairy roots, while in the case of mature tissues, hairy roots developed only as a result of cambium transformation (Olszowska 1992). However, the ability to form embryogenic callus by cotyledons and leaf explants of $C$. abyssinica seedlings was proven to be similar (Furmanek and Banaś 2011). Nevertheless, in the presented experiments, only the leaf explants produced hairy roots. Therefore, it seems that other factors than the regeneration ability could affect the efficiency of A. rhizogenes transformation process.

In the present research, we implemented acetosyringone (4-acetyl-2,6-dimethoxyphenol) to A. rhizogenes growth medium, as well as to the culture media used for the growth of inoculated plant explants. It was probably the crucial factor for obtaining high transformation efficiency of C. abyssinica leaves. Such assumption could be drawn from earlier studies showing that application of acetosyringone significantly increases the efficiency of plant transformation with bacteria from the Agrobacterium genus (Kumar et al. 2006). Sheikholeslam and Weeks (1987) showed, for example, that incubation of A. tumefaciens, in the presence of $20 \mu \mathrm{M}$ acetosyringone, just before inoculation of Arabidopsis thaliana plants, resulted in a $60 \%$ efficiency of transformation, whereas the use of bacteria not pre-incubated with acetosyringone resulted in only 2-3\% efficiency. Pre-incubation of A. rhizogenes with 
Fig. 1 Growth of hairy roots of C. abyssinica on MS medium $+2 \%$ sucrose: a $\mathrm{MS}+500 \mathrm{mg} 1^{-1}$ Claforan $+500 \mathrm{mg}^{-1}$ Carbenicillin-4 weeks after infection, $\mathbf{b} \mathrm{MS}+0.1 \mathrm{mg} 1^{-1}$ NAA-6-week-old culture; c $\mathrm{MS}+0.1 \mathrm{mg}^{-1} \mathrm{NAA}-10$ week-old culture, d MS + $0.1 \mathrm{mg}^{-1}$ $\mathrm{NAA}+0.1 \% \mathrm{PVP}-14$-weekold culture
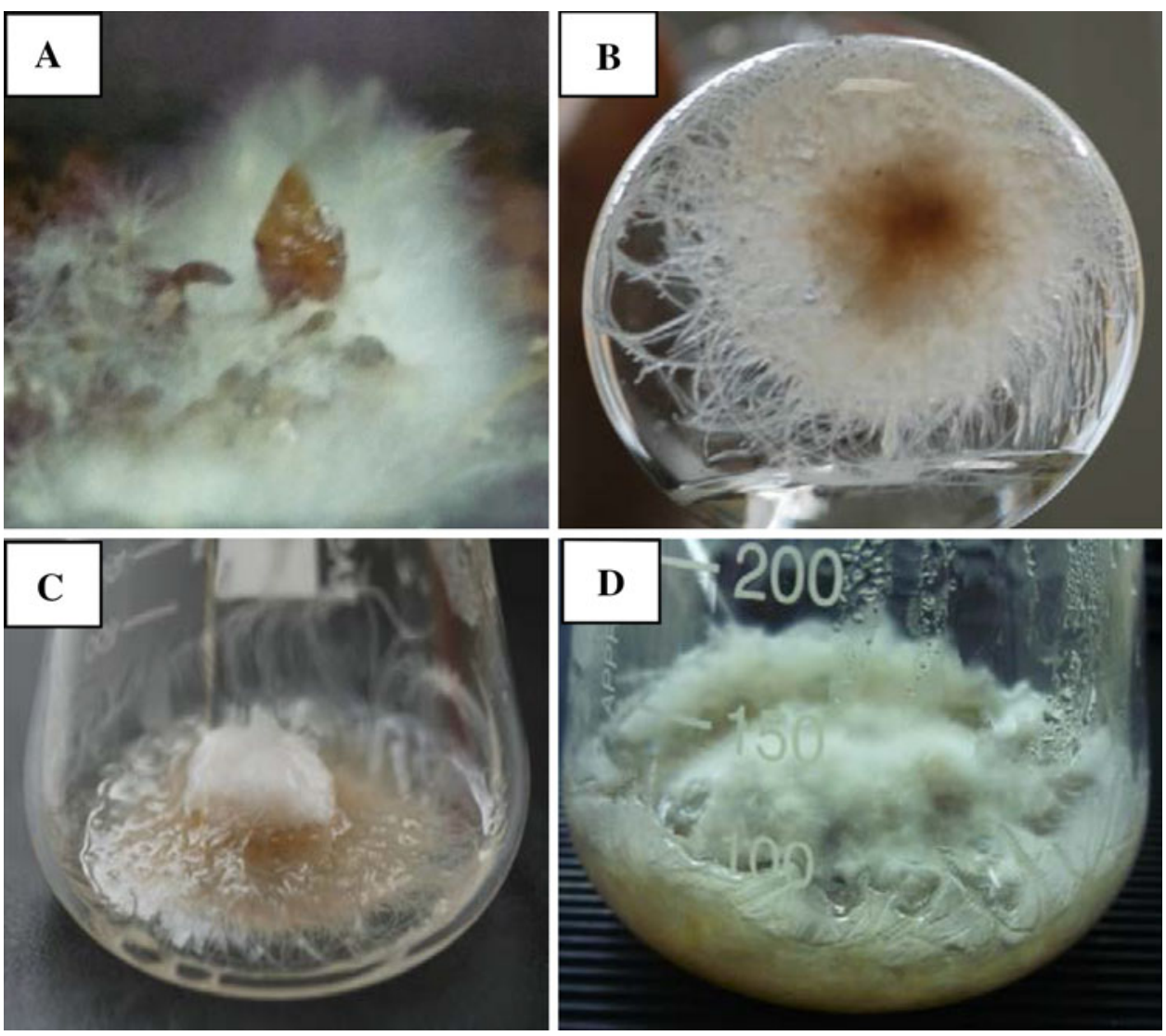

$100 \mu \mathrm{M}$ acetosyringone before transformation of Alhagi pseudoalhagi resulted in a fivefold increase in the transformation efficiency, compared to a protocol with untreated bacteria (Wang et al. 2001). These results can be explained by the fact that acetosyringone is excreted by wounded plant tissues and induces vir genes expression in the cells of A. rhizogenes, as well as takes part in chemotaxis of these bacteria (Flores and Medina-Bolivar 1995; Melchers et al. 1989). Therefore, addition of acetosyringone to the medium could stimulate these processes.

The data published so far indicate that the efficiency of transformation of the plants from Brassicaceae family (Crucifere) with A. rhizogenes varies from $1 \%$ (Brassica oleracea) to $43 \%$ (Brassica campestris) (Christey et al. 1997). Thus, the results obtained in the presented research (16\% efficiency) place $C$. abyssinica in the middle and can be considered satisfactory, especially in comparison to the transformation efficiency of $C$. abyssinica with A. tumefaciens. The protocols of $C$. abyssinica transformation developed and patented so far concern only the use of A. tumefaciens with efficiencies of 1.3-2.1\% ( $\mathrm{Li}$ et al. 2010; Engler and Montanez 2010). Similar to our results, transformation of other crucifers with A. rhizogenes was much more efficient, when leaves, rather than cotyledons, were inoculated with the bacteria (Christey et al. 1997).
Hairy root cultures can be grown on a medium without growth hormones, however, addition of 1-NAA leads to higher biomass accumulation (Shen et al. 1988). Roots are more sensitive to auxins than shoots, and a relatively low auxin concentration inhibits their growth. Thus, it is likely that transformation with $A$. rhizogenes changes the sensitivity of the transformed cells to this hormone. In the present research, hairy roots were cultured on a medium containing $0.1 \mathrm{mg} 1^{-1} \mathrm{NAA}$, and this concentration resulted in proper development of hairy root cultures (Fig. 1).

At the beginning of the study, hairy roots were grown in a liquid medium without polyvinylpyrrolidone (PVP). In such conditions, we observed intensive browning of the medium, as well as of the hairy roots culture. When the cultures were not passaged for a period longer than 3 weeks, the transformed roots showed serious signs of ageing (lack of growth and dying out of the culture). Addition of PVP to the medium significantly reduced the afore-mentioned symptoms. It is highly likely that the observed browning could result from intensive excretion of phenolic compounds. The added PVP was probably sequestering the phenolics from the media (PVP is commonly used for this purpose; Siegeland and Enns 1979; Maliyakal 1992) and thus, the cultures could intensify their 
development. After 50 days of culture, the biomass of hairy roots increased 27 -fold, both when PVP was added to the medium, and when it was not (Fig. 2). The differences in growth rate were not significant, though it is noteworthy that the hairy roots cultured with PVP were brighter. They could be passaged on fresh medium after 5-6 weeks of growth. We observed no darkening of the medium by phenolic compounds, or as a result of dying out of the hairy root culture.

To validate the transformation at the molecular level, a PCR analysis of the DNA isolated from the tested clones of hairy roots was conducted. During the DNA extraction (according to the modified method of Bekesiova et al. 1999), sodium sulphite (antioxidant) was implemented to protect DNA. Preliminary results indicated that the protection of DNA against oxidation was absolutely necessary. It is likely that during the cell lysis, phenolics are released, oxidised by cell oxidases, and subsequently bound irreversibly with nucleic acids which results in DNA degradation (Varma et al. 2007). We used the primers for rolB and rolC genes for amplification of genomic DNA of the analysed hairy root cultures and found that both of the tested genes were present in the analysed DNA (product length of 423 and $626 \mathrm{bp}$, respectively). PCR performed with the primers for $v i r \mathrm{G}$ gene (present on the bacterial $\mathrm{Ri}$ plasmid, outside the T-DNA) confirmed the absence of this fragment (product length $273 \mathrm{bp}$ ) in the analysed DNA (Fig. 3). Thus, we got a confirmation that the analysed hairy roots clones were free of bacteria and that rolB and rolC genes were present in their genomic DNA.

\section{Root lipids}

The acyl-lipid content (shown as the sum of fatty acids) varied significantly between the analysed clones of hairy roots, and oscillated between 15 and $53 \mathrm{nmol} \mathrm{FA} / \mathrm{mg}$ (4.5 and $14.7 \mathrm{mg} / \mathrm{g}$ DW, respectively) (Table 2). The observed differences were probably related to different physiological

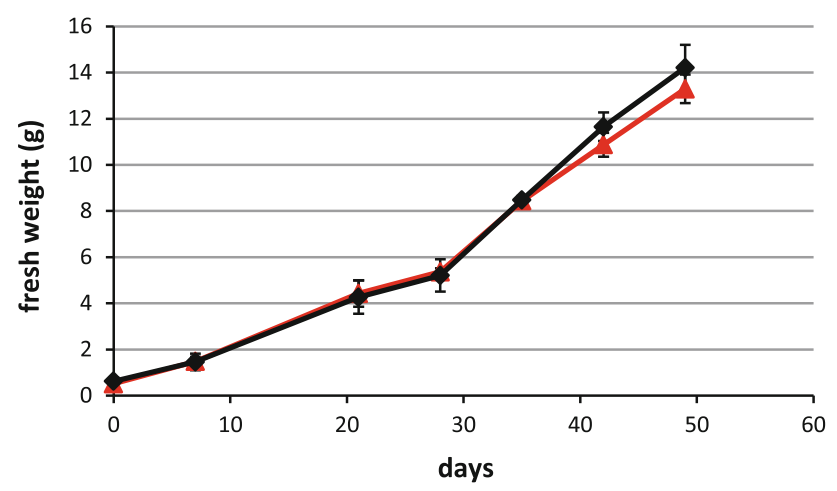

Fig. 2 Dynamics of growth of C. abyssinica hairy roots during 50 days. Black line growth of hairy roots on $\mathrm{MS}+0.1 \mathrm{mg} 1^{-1} \mathrm{NAA}+0.1 \% \mathrm{PVP}$, red line growth of hairy roots on $\mathrm{MS}+0.1 \mathrm{mg} 1^{-1} \mathrm{NAA}$ (colour figure online) status of the analysed clones; however, these differences were not always visible. For example, clones $\mathrm{C}$ and $\mathrm{E}$ did not differ visually (both were cultured during the same time and appeared to be in good physiological condition), but the lipid content in clone $\mathrm{E}$ was approximately $40 \%$ higher than in clone $\mathrm{C}$ (Table 2). The clones $\mathrm{G}$ and $\mathrm{H}$ with the lowest lipid content showed, however, clear ageing symptoms. We observed elevated levels of free fatty acids (16 and $30 \%$ of lipids in clone $\mathrm{F}$ and $\mathrm{G}$, respectively; Table 3). Considering the fact that all the clones studied were obtained at the same time, it is possible that the variation in lipid content is not associated with the age of the clones but rather is a direct result of the Agrobacterium-mediated transformation. Incorporation of bacterial T-DNA into the plant chromosome is totally random and varies in terms of the number of incorporated fragments and their localisation in the chromosomes (Ambros et al. 1986; Jeon et al. 2000). Thus, it is reasonable to expect that the physiological effect of transformation could also be different. It seems that such variations in transformation effects occurred in the conducted experiments as well. Some of the obtained clones exhibited accelerated lipid catabolism. Nevertheless, from the results we got so far, it is impossible to judge, if it was the cause of accelerated ageing or a result of other effects influencing this process.

Acyl-lipids content in the non-transformed roots of C. abyssinica, cultured in vitro, on MS medium solidified with agar, was somewhat similar to that of the transformed roots (41 nmol FA/mg DW; Table 2). This may suggest that the lipid metabolism in hairy roots (which are in good physiological condition) does not differ significantly from

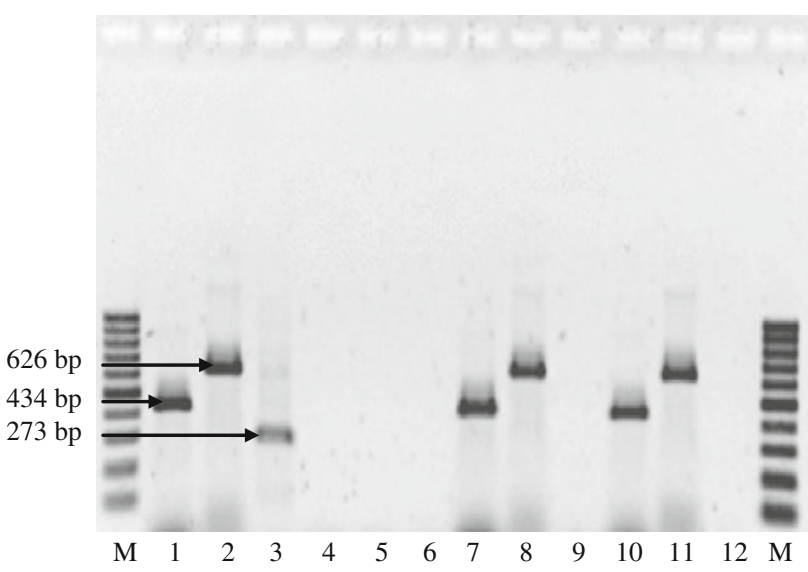

Fig. 3 PCR analysis of Agrobacterium rhizogenes A4 (lanes 1-3, positive control), non-Agrobacterium induced roots (lanes 4-6, negative control), Crambe abyssinica transformed with $A$. rhizogenes A4 (lanes 7-9) and ATCC 15834 (lanes 10-12). GeneRuler ${ }^{\mathrm{TM}} 100 \mathrm{bp}$ DNA ladder (lane $M$ ). Arrows show the amplified fragments of rolB (423 bp; lanes 1, 4, 7, 10), rolC (626 bp; lanes 2, 5, 8, 11), and vir $\mathrm{G}$ (273 bp; lanes 3, 6, 9, 12) genes. The PCR results for A. rhizogenes ATCC 15834 were the same as for strain A4 
Table 2 Lipid content (presented as a sum of fatty acids-FA) in hairy roots and non-Agrobacterium induced roots of $C$. abyssinica

\begin{tabular}{llr}
\hline $\begin{array}{l}\text { Transformed roots of } C \text {. abyssinica } \\
\text { (selected clones) }\end{array}$ & $\begin{array}{l}\sum_{(\mathrm{nmol})} \mathrm{FA} / \mathrm{mg} \mathrm{DW} \\
\text { A }\end{array}$ & \multicolumn{1}{l}{ DW $\mathrm{FA} \mathrm{mg/g}$} \\
\hline $\mathrm{A}$ & $52.47 \pm 0.91$ & $14.7 \pm 0.25$ \\
$\mathrm{C}$ & $48.85 \pm 0.57$ & $13.55 \pm 0.16$ \\
$\mathrm{D}$ & $38.33 \pm 0.04$ & $10.73 \pm 0.03$ \\
$\mathrm{E}$ & $46.63 \pm 1.05$ & $13.1 \pm 0.03$ \\
$\mathrm{~F}$ & $53.15 \pm 0.92$ & $14.7 \pm 0.25$ \\
$\mathrm{G}$ & $25.13 \pm 1.47$ & $7.23 \pm 0.43$ \\
$\mathrm{H}$ & $17.63 \pm 0.36$ & $5.2 \pm 0.12$ \\
I & $15.45 \pm 1.06$ & $4.5 \pm 0.32$ \\
Non-Agrobacterium induced roots & $40.97 \pm 2.23$ & $11.43 \pm 0.62$ \\
$\quad$ of $C$. abysinica & & \\
\hline
\end{tabular}

Values expressed as mean \pm standard deviation $(n \geq 3)$

Non-Agrobacterium induced roots of $C$. abyssinica (8-week-old plants with roots grown on MS medium solidified with agar)

$A, B, C, D, E$ hairy roots clones of $C$. abyssinica in good physiological condition, $F, G, H, I$ hairy roots clones of $C$. abyssinica exhibiting ageing symptoms, $D W$ dry weight

the lipid metabolism of the non-Agrobacterium induced roots. This assumption is also supported by the lipid composition in both types of roots (Table 3 ). Polar lipids were the dominant lipid class, both in the hairy roots and the non-Agrobacterium induced roots of $C$. abyssinica, and accounted for about $75 \%$ of acyl-lipids. Furthermore, we found diacylglycerols (DAG), free fatty acids (FFA), triacylglycerols (TAG), and sterol esters (SE). Additionally, in all examined samples, an unidentified lipid (X), localised just above the polar lipids on the TLC plate (developed with hexane:diethyl ether:acetic acid: 70/30/1 v/v/v), accounted for about $9 \%$ and about $3 \%$ of acyl-lipids of the hairy roots and of the non-Agrobacterium induced roots, respectively. In contrast to lipid $\mathrm{X}$, no clear tendencies concerning other lipid classes can be observed due to natural variability of hairy roots. The observed differences could be connected with the transformation or with the differences in the physiological status of the analysed roots. The observed variations in lipid composition between the clones of hairy roots showing and not showing ageing symptoms suggest, however, that, at least partially, these differences could be explained by the condition of the analysed roots.

Polar lipids were the major class of lipids in the hairy roots of Catharanthus roseus (Toivonen et al. 1992) and E. acanthocarpum (Cequier-Sánchez et al. 2008). These lipids are the main constituents of membranes. However, the precise role of neutral lipids in the roots remains unclear. Further research is necessary to clarify if they serve only as a storage material, or play also a certain role in the function of membranes.

Fatty acids composition of the lipids of both the hairy roots and the non-Agrobacterium induced roots of C.abyssinica did not differ significantly. The observed differences were only in terms of quantity, but not in terms of chemical composition. $\alpha$-Linolenic acid was the dominant fatty acid in the lipids of both types of roots, and accounted for about $27 \%$ of all fatty acids. Palmitic acid content amounted to about 17-20\% and linoleic acid to about $12-15 \%$. Among the lipids of the non-Agrobacterium induced roots, oleic acid accounted for about $5 \%$ of total fatty acids, but in the hairy roots, only for about $1 \%$. All other identified fatty acids content ranged from 1 to $4 \%$, and there were no significant differences between both types of roots (Table 4). Apart from the fatty acids cochromatographed with known standards, we also found an unidentified fatty acid with retention time between stearic and oleic acid in the lipids of both hairy roots and the nonAgrobacterium induced roots of $C$. abyssinica (about 21 and $16 \%$, respectively). Separation of fatty acid methyl esters of $C$. abyssinica root lipids using silver ion thin layer chromatography revealed that this unknown fatty acid is co-chromatographed with trans-monoenoic fatty acid methyl esters. Thus, it is probably a trans isomer of oleic acids. However, the position of the double bond needs to be identified. This fatty acid was not present, neither in the lipids of $N$. tabacum roots (data not presented) nor in the root lipids of a few other plants (Banas et al. 2011).

Table 3 Lipid composition of non-Agrobacterium-induced roots and hairy roots of Crambe abyssinica

\begin{tabular}{|c|c|c|c|c|c|c|c|}
\hline \multirow[t]{2}{*}{ Analysed roots } & \multicolumn{7}{|c|}{ Lipid classes (\% of total fatty acid) } \\
\hline & $\begin{array}{l}\text { Polar } \\
\text { lipids }\end{array}$ & $\mathrm{X}$ & DAG & FFA & TAG & SE & Other \\
\hline Non-Agrobacterium induced roots & $74.5 \pm 0.6$ & $2.7 \pm 0.1$ & $2.4 \pm 2.3$ & $9.5 \pm 2.3$ & $8.5 \pm 2.2$ & $1.1 \pm 0.2$ & $1.4 \pm 0.4$ \\
\hline $\begin{array}{l}\text { Hairy roots in good physiological condition (clones: } \\
\text { A, B, C, D, E) }\end{array}$ & $74.8 \pm 3.4$ & $8.9 \pm 3.2$ & $3.6 \pm 1.2$ & $5.1 \pm 1.7$ & $5.1 \pm 2.4$ & $1.2 \pm 0.5$ & $1.3 \pm 0.6$ \\
\hline Ageing hairy roots-clone $\mathrm{F}$ & $48.4 \pm 1.1$ & $21.4 \pm 0.4$ & $2.9 \pm 0.3$ & $16.3 \pm 2.2$ & $0.7 \pm 0.2$ & $2.0 \pm 0.1$ & $8.3 \pm 1.4$ \\
\hline Ageing hairy roots-clone $\mathrm{G}$ & $40.9 \pm 2.3$ & $4.8 \pm 1.3$ & $7.0 \pm 1.3$ & $30.0 \pm 2.3$ & $3.3 \pm 0.9$ & $2.5 \pm 0.3$ & $11.5 \pm 1.2$ \\
\hline
\end{tabular}

Mean \pm standard deviation presented

$X$ unidentified lipids, $D A G$ diacylglycerols, $F F A$ free fatty acids, $T A G$ triacylglycerols, $S E$ sterol esters 


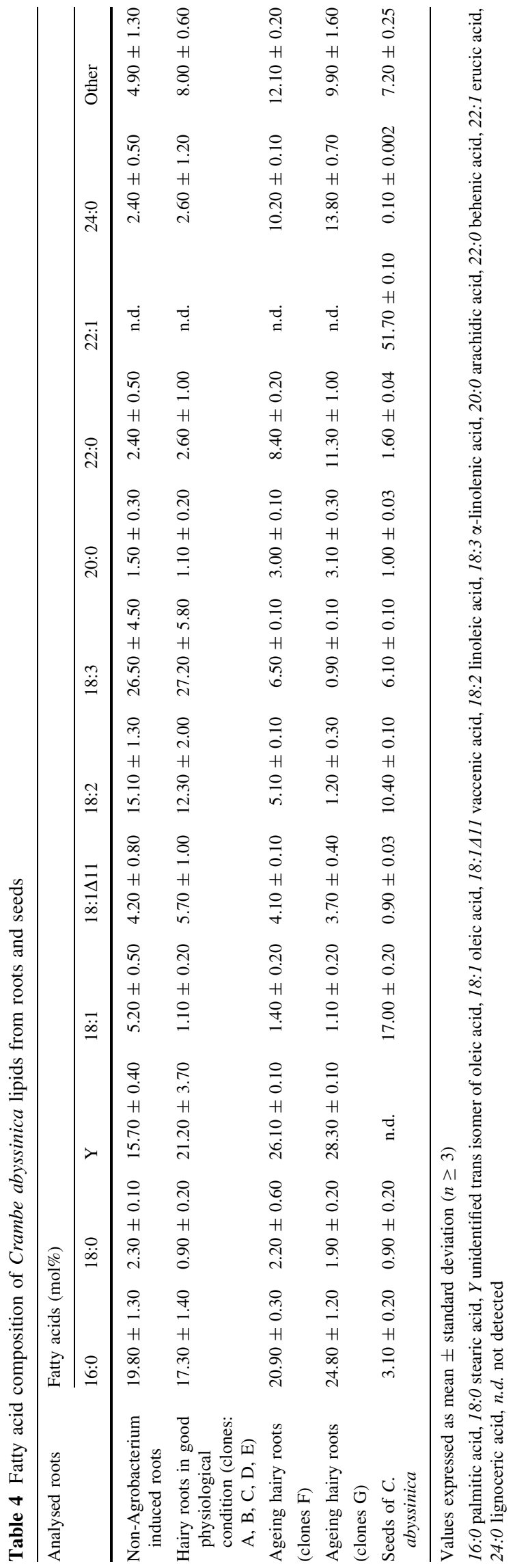

Nevertheless, at present, it is impossible to conclude, whether it is specific only to crambe or also to other plant species.

No differences in the fatty acid composition of hairy roots and the non-Agrobacterium induced roots were also observed in $C$. roseus. The main fatty acids found in the lipids extracted from both types of roots were palmitic, oleic, linoleic, and linolenic acids, and they accounted for more than $95 \%$ of the total amount of fatty acids (Toivonen et al. 1992).

Erucic acid is used in the manufacture of numerous industrial products, such as lubricants, surfactants, cosmetics and polyesters (Tao and He 2005; Vargas-Lopez et al. 1999). Current studies are focused on the development of high erucic acid oil crops which would substantially reduce the cost of erucic acid production ( $\mathrm{Li}$ et al. 2012; Nath et al. 2009). Erucic acid was not detected in the hairy roots of $C$. abyssinica, which suggests that this system is not actually suited for production of this fatty acid. The most recent studies on plant oils are focused on investigating alternative methods of producing oil in different organs and tissues such as leaves, tubers or roots (Carlsson et al. 2011). Further research is needed to assess whether these systems will be able to compete with seed oil production.

In conclusion, it seems that hairy roots could be a very useful material for studying both anabolism and catabolism of root lipids. The method of transformation using $A$. rhizogenes, that we developed, is an effective way of obtaining this type of roots.

Author contribution BG carried out the experiments, analysed the data and drafted the manuscript. TF carried out the experiments. MM carried out the experiments and was also involved in preparing the manuscript. $\mathrm{AB}$ and $\mathrm{AK}$ supervised the work and were also involved in preparing the manuscript. All authors have read and approved the final version of this manuscript.

Acknowledgments This work was supported by Grants BW/M0305-0580-0 and 2011/01/N/NZ1/03648.

Open Access This article is distributed under the terms of the Creative Commons Attribution License which permits any use, distribution, and reproduction in any medium, provided the original author(s) and the source are credited.

\section{References}

Ambros PF, Matzke AJM, Matzke MA (1986) Localization of Agrobacterium rhizogenes T-DNA in plant chromosomes by in situ hybridization. EMBO J 5(9):2073-2077

Banaś W, Furmanek T, Banaś A (2011) Effect haloxyfop and alloxydim applied separately and in combination with salicylic acid, diphenylamine, or norflurazon on the root growth and fatty 
acid composition of the selected species of grasses and dicotyledonous plants. Acta Sci Pol, Agricultura 10(3):3-13

Bekesiova I, Nap JP, Mlynarova L (1999) Isolation of high quality DNA and RNA from leaves of the carnivorous plant Drosera rotundifolia. Plant Mol Biol Rep 17:269-277

Bligh EG, Dyer WJ (1959) A rapid method of total lipid extraction and purification. Can J Biochem Physiol 37:911-917

Bonhomme V, Laurain-Mattar D, Lacoux J, Fliniaux MA, JacquinDubreuil A (2000) Tropane alkaloid production by hairy roots of Atropa belladonna obtained after transformation with Agrobacterium rhizogenes 15834 and Agrobacterium tumefaciens containing rol $A, B, C$ genes only. J Biotechnol 81:151-158

Cai Z, Kastell A, Knorr D, Smetanska I (2012) Exudation: an expanding technique for continuous production and release of secondary metabolites from plant cell suspension and hairy root cultures. Plant Cell Rep 31:461-477

Carlsson AS, Yilmaz JL, Green AG, Stymne S, Hofvander P (2011) Replacing fossil oil with fresh oil-with what and for what? Eur J Lipid Sci Technol 113(7):812-831

Cequier-Sánchez E, Rodríguez C, Ravelo AG, Zárate R (2008) Dichloromethane as a solvent for lipid extraction and assessment of lipid classes and fatty acids from samples of different natures. J Agric Food Chem 56(12):4297-4303

Cequier-Sánchez E, Rodríguez C, Dorta-Guerra R, Ravelo AG, Zárate R (2011) Echium acanthocarpum hairy root cultures, a suitable system for polyunsaturated fatty acid studies and production. BMC Biotechnol 11:42

Christey MC, Sinclair BK, Braun RK, Wyke L (1997) Regeneration of transgenic vegetable brassicas (Brassica oleracea and B. campestris) via Ri-mediated transformation. Plant Cell Rep 16:587-593

David C, Tempe J (1988) Genetic transformation of cauliflower (Brassica oleracea L. var. botrytis) by Agrobacterium rhizogenes. Plant Cell Rep 7:88-91

Engler D, Montanez B (2010) Transformation of Crambe abyssinica. Mendel Biotechnology Inc. Haward, CA. USA. Patent Application Publication. 2010/0281565 A1

Flores H, Medina-Bolivar F (1995) Root culture and plant natural products: 'Unearthing' the hidden half of plant metabolism. Plant Tissue Cult Biotechnol 1:59-74

Furmanek T, Banaś W (2011) Embryogenic callus formation by cotyledon and leaf explants of Crambe abyssinica seedlings. BioTechnologia 92(2):209-213

Georgiev MI, Agostini E, Ludwig-Muller J, Xu J (2012) Genetically transformed roots: from plant disease to biotechnological resource. Trends Biotechnol 30(10):528-537

Hamill JD, Parr AJ, Rhodes MJC, Robins RJ, Walton NJ (1987) New routes to plant secondary products. Nat Biotechnol 5:800-804

Hunter CS, Neill SJ (1990) Induction of hairy roots by Agrobacterium rhizogenes and growth of hairy roots in vitro. In: Pollard JW, Walker JM (eds) Methods in molecular biology, vol 6, Plant Cell and Tissue Culture, pp 279-288

Jeon J, Lee S, Jung K, Jun S, Jeong D, Lee J, Kim C, Jang S, Lee S, Yang K, Nam J, An J, Han M, Sung R, Choi H, Yu J, Choi J, Cho S, Cha S, Kim S, An G (2000) T-DNA insertional mutagenesis for functional genomics in rice. Plant J 22(6):561-570

Krolicka A, Szpitter A, Stawujak K, Baranski R, Gwizdek-Wisniewska A, Skrzypczak A, Kaminski M, Lojkowska E (2010) Teratomas of Drosera capensis var. alba as a source of naphthoquinone: ramentaceone. Plant Cell Tissue Organ Cult 103:285-292

Królicka A, Staniszewska I, Bielawski K, Maliński E, Szafranek J, Łojkowska E (2001) Establishment of hairy root cultures of Ammi majus. Plant Sci 160:259-264

Kumar V, Sharma A, Prasad BCN, Gururaj HB, Ravishankar GA (2006) Agrobacterium rhizogenes mediated genetic transformation resulting in hairy root formation is enhanced by ultrasonication and acetosyringone treatment. Electron J Biotechnol 9(4):1-9
Li X, Ahlman A, Yan X, Lindgren H, Zhu L (2010) Genetic transformation of the oilseed crop Crambe abyssinica. Plant Cell Tissue Organ Cult 100:149-156

Li X, van Loo EN, Gruber J, Fan J, Guan R, Frentzen M, Stymne S, Zhu L-H (2012) Development of ultra-high erucic acid oil in the industrial oil crop Crambe abyssinica. Plant Biotechnol J 10(7): $862-870$

Maliyakal EJ (1992) An efficient method for isolation of RNA and DNA from plants containing polyphenolics. Nucleic Acids Res 20(9):2381

Mankin SL, Hill DS, Olhoft PM, Toren E, Wenck AR, Nea L, Xing L, Brown JA, Fu H, Ireland L, Jia H, Hillebrand H, Jones T, Song H-S (2007) Disarming and sequencing of Agrobacterium rhizogenes strain K599 (NCPPB2659) plasmid pRi2659. In Vitro Cell Dev Biol Plant 43:521-535

Melchers LS, Regensburgtuink AJG, Schilperoort RA, Hooykaas PJJ (1989) Specificity of signal molecules in the activation of Agrobacterium virulence gene expression. Mol Microbiol 3:969-977

Miller JH (1972) Experiments in molecular genetics. Cold Spring Harbor Laboratory Press, Cold Spring Harbor

Nath UK, Becker CH, Möllers C (2007) Increasing erucic acid content in rapeseed (Brassica napus L.). In: Proceedings of the 12th international rapeseed congress, Wuhan, China, vol I, pp 173-176

Nath UK, Wilmer JA, Wallington EJ, Becker HC, Möllers C (2009) Increasing erucic acid content through combination of endogenous low polyunsaturated fatty acids alleles with $L d$ LPAAT + Bn-fae 1 transgenes in rapeseed (Brassica napus L.). Theor Appl Genet 118(4):765-773

Olszowska O (1992) Korzenie transformowane roślin leczniczych. Biotechnologia 19:21-26

Porter JR (1991) Host range and implications of plant infection by Agrobacterium rhizogenes. Crit Rev Plant Sci 10:387-421

Sheikholeslam SN, Weeks DP (1987) Acetosyringone promotes high efficiency transformation of Arabidopsis thaliana explants by Agrobacterium tumefaciens. Plant Mol Biol 8:291-298

Shen WH, Petit A, Guern J, Tempé J (1988) Hairy roots are more sensitive to auxin than normal roots. PNAS USA 85(10):3417-3421

Siegeland NR, Enns RK (1979) Soluble polyvinylpyrrolidine and bovine serum albumin adsorb polyphenols from soybean suspension cultures. Plant Physiol 63:206-208

Tao C, He BB (2005) Enzymatic isolation and enrichment of erucic acid from HEA seed oils: current status. Trans ASAE 48(4):1471-1479

Tepfer D (1984) Transformation of several species of higher plants by Agrobacterium rhizogenes: sexual transmission of the transformer genotype and phenotype. Cell 37:959-967

Tiwari RK, Trivedi M, Guang ZC, Guo GQ, Zheng GC (2008) Agrobacterium rhizogenes mediated transformation of Scutellaria baicalensis and production of flavonoids in hairy roots. Biol Plant 52:26-35

Toivonen L, Laakso S, Rosenqvist H (1992) The effect of temperature on hairy root cultures of Catharanthus roseus: growth, indole alkaloid accumulation and membrane lipid composition. Plant Cell Rep 11:395-399

Tukey JW (1953) Some selected quick and easy methods of statistical analysis. Trans N Y Acad Sci 16(2):88-97

Vargas-Lopez JM, Wiesenborn D, Tostenson K, Cihacek L (1999) Processing of crambe for oil and isolation of erucic acid. J Am Oil Chem Soc 76:801-809

Varma A, Padh H, Shrivastava N (2007) Plant genomic DNA isolation: an art or a science. Biotechnol J 2:386-392

Wang Y, Peng P (1998) Intergeneric hybridization between Brassica species and Crambe abyssinica. Euphytica 101:1-7

Wang YM, Wang JB, Luo D, Jia JF (2001) Regeneration of plants from callus cultures of roots induced by Agrobacterium rhizogenes on Alhagi pseudoalhagi. Cell Res 11(4):279-282 